\title{
Composição e estrutura da vegetação de caatinga no sul do Piaú́, Brasil
}

\section{Composition and structure caatinga vegetation in south Piauí, Brazil}

\author{
Mailson Pereira de Souza ${ }^{*}{ }^{\text {; }}$ Joxleide Mendes da Costa Pires Coutinho ${ }^{2}$; Leovandes Soares da Silva ${ }^{3}$; Felipe Silva Amorim ${ }^{4}$ \\ Allyson Rocha Alves.
}

\begin{abstract}
Resumo: Visando contribuir para o conhecimento mais profundo a respeito da vegetação do sul do Piauí, e em especial às áreas de tensão ecológica, o presente trabalho objetivou inventariar, avaliando qualitativamente, o componente lenhoso de um trecho de Caatinga, no município de Bom Jesus, Piauí, Brasil. Para realização do levantamento foram alocadas 10 parcelas de 50x20 m (1000 m²), totalizando 1 ha de área amostrada, dispostas de forma contíguas para minimizar os possíveis efeitos de borda da área. Foram amostrados os indivíduos lenhosos vivos com diâmetro à altura do peito (DAP) $\geq 5 \mathrm{~cm}$, independente da altura. No levantamento foram encontradas 11 famílias, 25 gêneros e 27 espécies. Destas, as que se destacaram com os maiores valores de IVI foram: Cenostigma macrophyllum Tul., Combretum duarteanum Cambess., Erythroxylum laetevirens O.E.Schulz, Campomanesia pubescens (Mart. ex DC.) O. Berg., e Licania rigida Benth. O índice de diversidade de ShannonWiener ( $\mathrm{H}^{\prime}$ ) foi de 2,7 nats.ind ${ }^{-1}$. Para todos os efeitos de comparações, observou-se que a área estudada encontra-se em bom estado de conservação, não se constatando evidências diretas de exploração, tão pouco resquícios de incêndios florestais, apesar da proximidade da área de estudo com a zona urbana da cidade de Bom Jesus do Piauí. O fragmento é um ecótono vegetacional, com predomínio de espécies típicas da Caatinga.
\end{abstract}

Palavras-chave: Ecótono; Fitossociologia; Inventário.

Abstract: To contribute to the deeper knowledge of the southern Piaui vegetation, especially the areas of ecological tension, this study aimed to inventory and qualitatively assess the woody component of a Caatinga stretch in the municipality of Bom Jesus / PI, Brazil. To perform the survey plots were allocated $1050 \times 20 \mathrm{~m}\left(1000 \mathrm{~m}^{2}\right)$ totaling 1 ha of sampled area, arranged contiguous way to minimize the possible edge effects area. They sampled the living woody individuals with diameter at breast height $(\mathrm{DBH}) \geq 5 \mathrm{~cm}$, regardless of height. In the survey we found 11 families, 25 genera and 27 species. Of these, those that stood out with the highest IVI values were. Cenostigma macrophyllum Tul., Combretum duarteanum Cambess., Erythroxylum laetevirens O.E.Schulz , Campomanesia pubescens (Mart. ex DC.) O. Berg and Licania rigida Benth. The diversity index Shannon-Wiener $\left(\mathrm{H}^{\prime}\right)$ was 2,7 nats.ind-1. For all purposes of comparison, it was observed that the study area is in good condition, not finding to direct exploration evidence, so little remains of forest fires, despite the proximity of the study area with the urban area the city of Bom Jesus do Piauí. The fragment is a vegetative ecotone, with predominance of species typical of the Caatinga.

Key words: Ecotone, Phytosociology, Inventory.

\footnotetext{
*Autor para correspondência

Recebido para publicação em 21/11/2016; aprovado em 10/05/2017

${ }^{1}$ Mestrando em Ciências Florestais, Universidade Federal de Campina Grande/CSTR, Patos; (83)98777-4055, mps_51@hotmail.com.

${ }^{2}$ Bióloga, Dr, Professora do Depto de Ciências Biológicas, UFPI/CPCE/ Bom Jesus (PI), joxleide@ yahoo.com.br

${ }^{3}$ Doutorando em Ciências Florestais, Universidade Federal dos Vales do Jequitinhonha e Muricurí/Diamantina, leosoares.ef@gmail.com

${ }^{4}$ Mestrando em Ciências Florestais, Universidade Federal de Campina Grande/CSTR, Patos, felipeamorim36@hotmail.com

${ }^{5}$ Engenheiro Florestal, Dr., Professor do Depto de Ciências Vegetais, UFERSA, allyson@ufersa.edu.br.
} 


\section{INTRODUÇÃO}

O Bioma Caatinga tem seu domínio estendido por cerca de $900.000 \mathrm{~km}^{2}$, correspondendo a aproximadamente $54 \%$ de toda a região Nordeste e diretamente a $11 \%$ de todo o território brasileiro. Localizando-se entre as coordenadas geográficas $2^{0} 54^{\prime} \mathrm{S}$ e $17^{0} 21^{\prime} \mathrm{W}$, o referido bioma está presente em oito estados nordestinos: Ceará, Rio Grande do Norte, Paraíba, Pernambuco, Alagoas, Sergipe, sudoeste do Piauí, partes do interior da Bahia e do norte de Minas Gerais, bem como porções da ilha de Fernando de Noronha que também devem ser incluídas (ANDRADE et al., 2005).

A vegetação da Caatinga, em sua maioria, apresenta capacidade adaptativa para condições de déficit hídrico. Essa vegetação é classificada como xerófila; a mesma apresenta uma heterogeneidade em relação às fitofisionomias e estruturas, evidenciando, assim, uma dificuldade acerca da elaboração de esquemas de classificação capazes ou satisfatórios para contemplar as várias tipologias ocorrentes neste bioma (ANDRADE-LIMA, 1981; MONTEIRO et al., 2015).

A região na qual o bioma Caatinga está inserido apresenta terrenos cristalinos, necessariamente impermeáveis e terrenos sedimentares que apresentam uma boa capacidade de drenagem, permitindo assim um bom reservatório de água subterrânea. Há uma predominância de solos pouco desenvolvidos, com raras exceções, mineralmente ricos, na sua maioria pedregosos e com baixa capacidade de retenção de água, que se torna o fator limitante à produção primária nessa região (ALVES; et al., 2009).

Não obstante, a Caatinga vem sofrendo um processo de degradação acelerado, advindo do uso inadequado de seus recursos naturais, destacando-se como principais fatores o desmatamento e as queimadas. O uso da lenha seja esta para uso direto ou transformada em carvão, em ambos os casos abastecendo demandas domiciliares e industriais, na maioria das vezes é feita de forma descontrolada, ou seja, sem sustentabilidade ambiental (CALIXTO JÚNIOR; DRUMOND, 2014). Do ponto de vista econômico, o bioma Caatinga desempenha um importantíssimo papel para a população nordestina, pois seus recursos naturais são utilizados de forma direta e indireta, na geração de energia tanto para indústria e domicílios quanto para obtenção de produtos florestais não madeireiros. Apesar da importância desempenhada por este bioma, os autores destacam que o mesmo vem sendo explorado de forma irresponsável e insustentável, ocasionando a aceleração de processos degradantes (GARIGLIO, 2010).

Associado às negligências do uso, acrescenta-se o fato de a caatinga ser um dos tipos vegetacionais menos conhecido. E essas lacunas do conhecimento se ampliam à medida que essas áreas se permeiam com os biomas vizinhos. A citar o Estado do Piauí, que está localizado numa área de tensão ecológica, com vegetação de transição. Por causa da elevada heterogeneidade espacial e ambiental, sua cobertura vegetal apresenta-se como um complexo mosaico de tipos vegetacionais, que vão desde os mais secos, como as caatingas, distribuídas a Leste e Sudeste, passando pelos carrascos em sua parte Central e Nordeste; seguidos dos cerrados em sua porção Centro-Norte e Sudoeste, até os mais úmidos, como as Matas de babaçuais e florestas estacionais semidecíduas instaladas nos limites dos Estados do Piauí e
Maranhão, e nas depressões da bacia do Parnaíba (SAMPAIO, 2004).

O estudo da florística e da fitossociologia de uma floresta de caatinga é de suma importância, pois representa o passo inicial para o conhecimento ecológico dessa vegetação. Associado a sua estrutura e dinâmica, pode-se construir uma base teórica que subsidie a conservação dos recursos genéticos, a conservação de áreas similares e a recuperação de áreas ou fragmentos florestais degradados. É por meio dos levantamentos fitossociológicos que é possível estabelecer graus de dominância entre as espécies estudadas e avaliar a necessidade de se tomar medidas e estratégias que visem à preservação e conservação não apenas das unidades florestais, mas também de fragmentos florestais (CHAVES et al., 2013; BULHÕES et al., 2015).

Considerando a escassez de inventários florestais na região ecotonal do Sul do estado do Piauí, objetivou-se realizar um levantamento florístico e fitossociológico do componente arbóreo/arbustivo de um trecho de Caatinga, avaliando as condições de secundarizarão da vegetação natural em que se encontrava esse fragmento, visto que o mesmo se localiza nas proximidades urbanas do município de Bom Jesus, Piauí.

\section{MATERIAL E MÉTODOS}

\section{Localização e descrição da área de estudo}

O município de Bom Jesus está localizado na microrregião do Alto Médio Gurguéia, compreendendo uma área de $5.685,57 \mathrm{~km}^{2}$, tendo como limites ao norte os municípios de Currais e Santa Luz; ao sul: Gilbués, Monte Alegre, Redenção do Gurguéia e Curimatá; a leste: Santa Luz, Guaribas, Morro Cabeça no Tempo e o estado da Bahia e a oeste: Baixa Grande do Ribeiro e Gilbués. A sede municipal situa-se geograficamente a $09^{\circ} 04^{\prime} 26^{\prime \prime}$ de latitude sul e $44^{\circ} 21$ '32" de longitude oeste de Greenwich (altitude da sede a $277 \mathrm{~m}$ acima do nível do mar) e uma distância de $632 \mathrm{~km}$ de Teresina (AGUIAR; GOMES, 2004). As condições climáticas do município apresentam-se em temperaturas mínimas de $18^{\circ} \mathrm{C}$ e máximas de $36^{\circ} \mathrm{C}$, com clima quente e semiúmido. A precipitação pluviométrica média anual (com registro, na sede, de $900 \mathrm{~mm}$ ) é definida no Regime Equatorial Continental, com isoietas anuais em torno de 800 a $1200 \mathrm{~mm}$ e período chuvoso estendendo-se de novembro a maio. $\mathrm{O}$ trimestre mais úmido corresponde aos meses de Dezembro, Janeiro e Fevereiro (AGUIAR; GOMES, 2004).

Para a realização do levantamento fitossociológico foi considerada uma área de transição localizada na Fazenda Folha Vermelha (FFV), com aproximadamente 12 ha de extensão, distando cerca de $4 \mathrm{~km}$ do Campus Universitário Federal do Piauí Professora Cinobelina Elvas (UFPI/CPCE) e $9 \mathrm{~km}$ do centro urbano do município.

A maior parte dos solos da região são oriundos da bacia sedimentar do Parnaíba, tendo a área de estudo apresentada solo Latossolo amarelo. O fragmento inventariado situa-se numa área de transição, possuindo tanto espécies de cerrado quanto de caatinga. Devido sua heterogeneidade espaçoambiental, sua cobertura vegetal apresenta uma mistura florística, onde coexistem espécies dos biomas Cerrado e Caatinga, com uma matriz vegetacional a ser avaliada neste estudo. 


\section{Análise florística e fitossociológica}

Para análise dos parâmetros fitossociológicos foi utilizado o método de parcelas de área fixa de acordo com Muller-Dumbois e Ellenberg (1974). Foram alocadas 10 parcelas de $50 \times 20 \mathrm{~m}\left(1000 \mathrm{~m}^{2}\right)$ totalizando 1 ha de área amostrada. As parcelas foram dispostas de forma contígua para minimizar os possíveis efeitos de borda da área. Para demarcação e localização das parcelas foram utilizadas estacas de policloreto de polivinila (PVC) e fitilho de nylon, bússola e GPS, respectivamente.

Dentro das parcelas foram mensurados todos os indivíduos com diâmetro do caule à altura do peito (DAP) $\geq 5$ $\mathrm{cm}$, apresentando-se um método satisfatório, uma vez que incluiu os indivíduos arbóreos de grande porte como também aqueles de menor porte e que são importantes na composição do subosque florestal. Estes foram identificados com placas numeradas e anotados seu DAP, sua altura, além de seu nome vulgar e posteriormente procedeu-se a determinação taxonômica, em que todo o material botânico testemunho (vegetativo e reprodutivo) foi coletado para posterior confirmação da identificação. A identificação foi realizada com ajuda de especialistas, da literatura e de consultas ao acervo do Herbário Setorial Vale do Gurguéia (HVG/CPCE/UFPI).

Para análise dos dados foi utilizado o programa Fitopac 2.1, (SHEPHERD, 2011). Os parâmetros analisados foram aqueles comumente avaliados em estudos dessa natureza: Densidade Absoluta (DA); Densidade Relativa (DR); Frequência Absoluta (FA); Frequência Relativa (FR); Dominância Absoluta (DoA); Dominância Relativa (DoR); Índice do Valor de Cobertura (IVC) e Índice Valor do Importância (IVI) (FELFILI; REZENDE, 2003). Para a análise de diversidade florística foram obtidos o Índice de Shannon (H'), de dominância de Simpson (C) e equabilidade de Pielou (J').

Para análise da estrutura hipsométrica foi confeccionado um histograma com o número de indivíduos por classe de altura, sendo que a amplitude de classe foi $2,0 \mathrm{~m}$ e intervalo fixo de 2,0 $\mathrm{m}$ entre as classes. Para a estrutura diamétrica também foi feito um histograma relacionando o número de indivíduos por classe de diâmetro com o DAP (diâmetro a altura do peito) inicial de $8,0 \mathrm{~cm}$ e intervalos de $8,0 \mathrm{~cm}$ entre as classes.

O levantamento florístico foi realizado por meio da identificação das espécies ocorrentes no interior das 10 parcelas alocadas na área de estudo. O sistema de classificação adotado para a organização taxonômica das famílias foi o de APG IV (2016) denominado Angiosperm Phylogeny Group (A.P.G. IV) e a condição atual dos táxons, descrição e grafia foram consultados no site Flora do Brasil 2020 em Construção (http://floradobrasil.jbrj.gov.br).

\section{RESULTADOS E DISCUSSÃO}

A suficiência amostral, demonstrada pela curva coletora (Figura 1) somente estabilizou a partir da oitava parcela amostrada, onde houve uma redução no número de novas espécies descobertas, ou seja, aos $8000 \mathrm{~m}^{2}$, cujo $100 \%$ do número das espécies inventariadas já haviam sido registradas. A partir desse ponto houve uma estagnação no número de espécies, indicando ser satisfatória a amostragem realizada para a área em estudo, de modo a atingir o mínimo de parcelas a ser utilizadas para caracterização da composição florística do fragmento estudado.

Figura 1. Representação gráfica da suficiência amostral das espécies inventariadas em um fragmento de Caatinga na F.F. $\mathrm{V}$, Bom Jesus, Brasil.

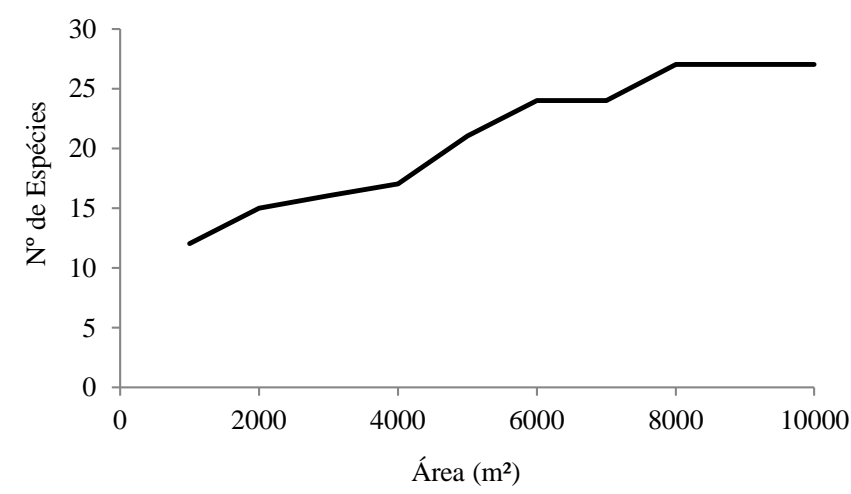

No levantamento realizado no trecho de Caatinga foram amostrados 723 indivíduos vivos, pertencentes a 11 famílias, 27 espécies e 25 gêneros (Tabela 1). Os valores apresentados para Densidade Total e Área Basal foram, respectivamente, 723 ind.hat ${ }^{-1}$ e $8,88 \mathrm{~m}^{2} \mathrm{ha}^{-1}$, sendo inferiores aos valores apresentados na maioria dos levantamentos aqui comparados, como aos encontrados por Lemos e Rodal, (2002); Guedes et al. (2012); Alves et al. (2013); e Sanquetta et al. (2014). No entanto, observou-se uma superioridade em relação a alguns levantamentos, ganhando destaque sobre Calixto Júnior e Drumond, (2014); Dias et al. (2014) e Ferraz et al. (2013). É interessante ressaltar a dificuldade de comparação dos valores entre os diferentes trabalhos quantitativos em decorrência da falta de padronização e uniformidade dos métodos de amostragem e dos critérios de inclusão aceitos pelos mesmos. Portanto, a inferioridade aqui presente, relacionada à Densidade Total e consequentemente Área Basal, se dá devido a adoção de um método de inclusão diferenciado (DAP $\geq 5 \mathrm{~cm}$ ), cujo diâmetro aceitável é bem maior que os dos encontrados na maioria dos levantamentos dessa natureza.

Comparando a listagem florística do presente estudo com algumas de áreas de Caatinga do Piauí e do Nordeste, observa-se que a composição se difere da maioria das áreas de Caatinga do Cristalino, como é o caso da listagem citada por Calixto Júnior e Drummond (2014). Quando comparada com Castro et al., (2009), ao classificar a fitodiversidade transicional da Serra Vermelha também no sul do Piaú, observa-se que para as manchas de Caatinga também existe uma semelhança bastante relevante na listagem florística dos dois estudos. Isso ocorre devido às duas áreas de estudos estarem localizadas numa região de ecótono geograficamente próximas e que apresentam semilares no que tange à composição florestal.

Reforça-se a caracterização da FFV e para tal, a importância da comparação para a determinação da composição vegetal. Portanto constata-se que esta apresenta características marcantes de áreas de tensão ecológica, também conhecida como áreas de transição ou ecótono, apresentando tanto espécies consideradas naturais da Caatinga, a citar Pityrocarpa moniliformis, Licania rigida, Ximenia americana, Manihot carthagenensis, quanto espécies que ocorrem nos dois ambientes, Caatinga e Cerrado, como Copaifera lagsdorfii, Brosimum gaudichaudii, Hymenaea stigonocarpa. 
Tabela 1. Espécies amostradas em Fazenda no município de Bom Jesus, Piauí, Brasil, com seus respectivos nomes vulgares e bioma típico. CAA - caatinga, CER - cerrado, FES - floresta estacional semidecíduas, AA - área antrópica.

\begin{tabular}{|c|c|c|c|}
\hline Famílias/Espécies & Vernáculo & Vegetação & Origem/ Endemismo \\
\hline ANNONACEAE & & & \\
\hline Morfoespécie 1 & Cundurú & CAA & \\
\hline APOCYNACEAE & & & \\
\hline $\begin{array}{l}\text { Aspidosperma pyrifolium Mart. \& Zucc. } \\
\text { CHRYSOBALANACEAE }\end{array}$ & Pequiá & CAA/CER & Nativa \\
\hline $\begin{array}{l}\text { Licania rigida Benth. } \\
\text { COMBRETACEAE }\end{array}$ & Oiticica & CAA/CEE/FES & Nat/ Endêmica \\
\hline Combretum duarteanum Cambess. & Vaqueta & CAA/CER/AA & Nativa \\
\hline $\begin{array}{l}\text { Terminalia actinophylla Mart. } \\
\text { EUPHORBIACEAE }\end{array}$ & - & CAA/CER & Nat/ Endêmica \\
\hline $\begin{array}{l}\text { Manihot carthagenensis } \\
\text { (Jacq.) Müll.Arg. } \\
\text { ERYTHROXYLACEAE }\end{array}$ & Maniçoba & CAA/AA & Nativa \\
\hline $\begin{array}{l}\text { Erythroxylum laetevirens O.E.Schulz } \\
\text { FABACEAE }\end{array}$ & Catuabinha & CAA/CER/FES & Nativa \\
\hline Bauhinia forficata Link subesp. forficata & Pata-de-vaca & CAA/AA & Nat/ Endêmica \\
\hline Bauhinia pulchella Benth. & Miroró-de-bode & CER/FES & Nativa \\
\hline Cenostigma macrophyllum Tul. & Canela-de-velho & Caatinga/Cerrado & Nativa \\
\hline Copaifera lagsdorffii Desf. & Pau-d'óleo & CER/FES/ AA & Nativa \\
\hline Dalbergia cearensis Ducke & Violete & CAA/FES & Nat/ Endêmica \\
\hline Diptychandra sp & Birro-amarelo & CAA/CEE/FES & Nativa \\
\hline Hymenaea stigonocarpa Mart. ex Hayne & Jatobazinho & CAA/CER/FES/AA & Nativa \\
\hline Mimosa tenuiflora (Willd.) Poir. & Jurema-preta & CAA/AA & Nativa \\
\hline Mimosa verrucosa Benth. & Jurema-branca & CAA/CER/AA & Nat/ Endêmica \\
\hline Morfoespécie 2 & Coração-de-negro & Caatinga & - \\
\hline Morfoespécie 3 & Regeto & Caatinga & - \\
\hline Piptadenia stipulacea (Benth.) Ducke & Unha-de-gato & Caatinga & \\
\hline Pityrocarpa moniliformis Benth. & Angico de bezerro & CAA & Nat/ Endêmica \\
\hline Pterodon emarginatus Vogel & Birro-preto & CEE/FES & Nativa \\
\hline $\begin{array}{l}\text { Swartzia cf. flaemingii Raddi } \\
\text { MALVACEAE }\end{array}$ & Banha-de-galinha & CER & Nat/ Endêmica \\
\hline $\begin{array}{l}\text { Ceiba glaziovii (Kuntze) K.Schum. } \\
\text { MORACEAE }\end{array}$ & Barriguda & CAA & Nat/ Endêmica \\
\hline $\begin{array}{l}\text { Brosimum gaudichaudii Trécul } \\
\text { MYRTACEAE }\end{array}$ & Inharé & CAA/CER/AA & Nativa \\
\hline Campomanesia pubescens (Mart. ex DC.) O. Berg. & Guabiraba & CAA/CER/FES & Nat/ Endêmica \\
\hline $\begin{array}{l}\text { Myrcia tomentosa (Aubl.) DC. } \\
\text { OLACACEAE }\end{array}$ & Goiaba-brava & CAA/CER/FES & - \\
\hline Ximenia americana $\mathrm{L}$. & Ameixa & CAA & Nativa \\
\hline
\end{tabular}

Das famílias amostradas na área de estudo, a Fabaceae foi a mais representativa com 15 espécies (Caesalpiniodeae, 6 espécies; Papilionoideae, 5 e Mimosoideae, 4), seguidas por Combretaceae e Myrtaceae com 2 espécies, cada. Essas famílias detiveram 70,3\% das espécies, enquanto que 72,7\% das famílias apresentaram apenas uma espécie. Fabaceae e Euphorbiaceae são apontadas como as famílias que apresentam o maior número de espécies em diversos levantamentos florísticos com espécies lenhosas na caatinga (GUEDES et al., 2012; FERRAZ et al., 2013;CALIXTO JÚNIOR; DRUMOND, 2014; LEITE et al., 2015).

Em se tratando de valores de IVI, destacaram-se as famílias Fabaceae-Caesalpiniodeae, Combretaceae, Myrtaceae e Erythroxylaceae, perfazendo 57,1 \% do IVI total (Tabela 2).

As espécies que detiveram o maior número de ocorrências consideradas dominantes na fisionomia foram: Cenostigma macrophyllum, Erythroxylum laetevirens,
Combretum duarteanum, Campomanesia pubescens, Licania rigida, totalizando $58 \%$ da densidade total do fragmento estudado. Estas mesmas espécies obtiveram as maiores frequências relativas, confirmando, assim, a predominância de ambas no fragmento.

Observou-se que a espécie Cenostigma macrophyllum foi à de maior destaque, pois apresentou o maior número de indivíduos e, consequentemente, o maior valor de frequência e densidade relativa $(14,25 \%)$. Além disso, obteve o maior valor de dominância relativa $(19,60 \%)$, tornando-se, assim, a primeira espécie com maior IVI da população amostrada. De acordo com Lemos e Rodal (2002), áreas sobre solos sedimentares, como é o caso do local de estudo, costumam a apresentar um grande número de espécies da família Fabaceae-Caesalpinioideae, onde a espécie aqui demonstrada apresenta uma ampla distribuição nos ambientes caducifólios do semiárido nordestino. 
Tabela 2. Famílias e subfamílias e seus parâmetros fitossociológicos. N - número de indivíduos; Nsp- Número de espécies; DA - densidade absoluta (ind.ha ${ }^{-1}$ ); DR - densidade relativa (\%); DoA - dominância absoluta ( $\left.\mathrm{m}^{2} / \mathrm{ha}\right)$; DoR - dominância relativa (\%); IVI - índice do valor de importância (\%); FA- frequência absoluta (\%); FR- frequência relativa (\%) em uma área de Caatinga na F.F.V, Bom Jesus, Piauí, Brasil.

\begin{tabular}{|c|c|c|c|c|c|c|c|c|c|}
\hline FAMÍLIAS & $\mathbf{N}$ & Nsp & $\overline{\mathbf{D A}}$ & DR & DoA & DoR & FA & FR & IVI \\
\hline Fabaceae-Caesalpinioideae & 186 & 6 & 186,0 & 25,73 & 2,76 & 32,11 & 100,00 & 11,36 & 69,20 \\
\hline Combretaceae & 90 & 2 & 90,0 & 12,45 & 1,19 & 13,82 & 100,00 & 11,36 & 37,63 \\
\hline Myrtaceae & 87 & 2 & 87,0 & 12,03 & 0,87 & 10,15 & 100,00 & 11,36 & 33,55 \\
\hline Erythroxylaceae & 91 & 1 & 91,0 & 12,59 & 0,79 & 9,20 & 80,00 & 9,09 & 30,87 \\
\hline Fabaceae-Papilionoideae & 65 & 5 & 65,0 & 8,99 & 0,88 & 10,28 & 100,00 & 11,36 & 30,63 \\
\hline Chrysobalanaceae & 70 & 1 & 70,0 & 9,68 & 0,89 & 10,41 & 90,00 & 10,23 & 30,32 \\
\hline Fabaceae-Mimosoideae & 72 & 4 & 72,0 & 9,96 & 0,74 & 8,58 & 90,00 & 10,23 & 28,76 \\
\hline Annonaceae & 45 & 1 & 45,0 & 6,22 & 0,25 & 2,97 & 90,00 & 10,23 & 19,42 \\
\hline Moraceae & 6 & 1 & 6,0 & 0,83 & 0,12 & 1,39 & 40,00 & 4,55 & 6,76 \\
\hline Olacaceae & 5 & 1 & 5,0 & 0,69 & 0,04 & 0,48 & 30,00 & 3,41 & 4,58 \\
\hline Euphorbiaceae & 3 & 1 & 3,0 & 0,41 & 0,01 & 0,14 & 30,00 & 3,41 & 3,96 \\
\hline Malvaceae & 2 & 1 & 2,0 & 0,28 & 0,04 & 0,44 & 20,00 & 2,27 & 2,99 \\
\hline Apocynaceae & 1 & 1 & 1,0 & 0,14 & 0,00 & 0,03 & 10,00 & 1,14 & 1,33 \\
\hline Total & 723 & 27 & 723 & 100 & 8,88 & 100 & 880 & 100 & 300 \\
\hline
\end{tabular}

Erythroxylum laetevirens, Combretum duarteanum, Campomanesia pubescens e Licania rigida se destacam na população por apresentarem um grande número de indivíduos e consequentemente elevada frequência $(6,76 \% ; 5,41 \%$; $6,76 \%$ e 6,08). Ao comparar a lista florística e os parâmetros fitossociológicos de algumas espécies deste levantamento com outros realizados no Piauí e no Nordeste, observam-se algumas diferenças; isso pode ser evidenciado e enfatizado pelo fato da área em estudo localizar-se em uma região de

transição de biomas, onde a caatinga do cristalino e sedimentar se incorpora ao Cerrado, dando características peculiares ao fragmento estudado. As espécies Bauhinia forficata, Piptadenia cf stipulacea e Bauhinia pulchella foram as que obtiveram os menores valores para densidade, dominância e frequência (Tabela 3). A baixa presença de espécies de sucessão primária ou espécies pioneiras caracteriza o bom estado de conservação do fragmento estudado.

Tabela 3: Espécies e seus parâmetros fitossociológicos. N - número de indivíduos; DA - densidade absoluta (ind.ha ${ }^{-1}$ ); DR densidade relativa (\%); DoA - dominância absoluta $\left(\mathrm{m}^{2} / \mathrm{ha}\right)$; DoR - dominância relativa (\%); IVI - índice do valor de importância (\%); FA- frequência absoluta (\%); FR- frequência relativa (\%) em uma área de Caatinga na F.F.V, Bom Jesus Piauí, Brasil.

\begin{tabular}{|c|c|c|c|c|c|c|c|c|}
\hline Espécies & $\mathbf{N}$ & $\overline{\mathbf{D A}}$ & $\overline{\mathbf{D R}}$ & DoA & DoR & FA & FR & IVI \\
\hline Cenostigma macrophyllum & 103 & 103,0 & 14,25 & 1,68 & 19,60 & 90,00 & 6,08 & 39,92 \\
\hline Combretum duarteanum & 83 & 83,0 & 11,48 & 1,03 & 11,97 & 100,00 & 6,76 & 30,21 \\
\hline Erythroxylum laetevirens & 91 & 91,0 & 12,59 & 0,79 & 9,20 & 80,00 & 5,41 & 27,19 \\
\hline Licania rigida & 70 & 70,0 & 9,68 & 0,89 & 10,41 & 90,00 & 6,08 & 26,17 \\
\hline Campomanesia pubescens & 76 & 76,0 & 10,51 & 0,65 & 7,57 & 100,00 & 6,76 & 24,84 \\
\hline Pityrocarpa moniliformis & 63 & 63,0 & 8,71 & 0,70 & 8,19 & 90,00 & 6,08 & 22,99 \\
\hline Hymenaea stigonocarpa & 42 & 42,0 & 5,81 & 0,52 & 6,10 & 100,00 & 6,76 & 18,67 \\
\hline Morfoespécie 1 & 45 & 45,0 & 6,22 & 0,25 & 2,97 & 90,00 & 6,08 & 15,27 \\
\hline Diptychandra sp. & 20 & 20,0 & 2,77 & 0,31 & 3,62 & 90,00 & 6,08 & 12,47 \\
\hline Morfoespécie 2 & 29 & 29,0 & 4,01 & 0,22 & 2,55 & 70,00 & 4,73 & 11,30 \\
\hline Copaifera lagsdorfii & 18 & 18,0 & 2,49 & 0,23 & 2,68 & 70,00 & 4,73 & 9,90 \\
\hline Myrcia tomentosa & 11 & 11,0 & 1,52 & 0,22 & 2,57 & 70,00 & 4,73 & 8,82 \\
\hline Morfoespécie 3 & 12 & 12,0 & 1,66 & 0,17 & 2,01 & 60,00 & 4,05 & 7,72 \\
\hline Swartzia cf. flaemingii & 10 & 10,0 & 1,38 & 0,18 & 2,14 & 40,00 & 2,70 & 6,22 \\
\hline Dalbergia cf. cearensis & 7 & 7,0 & 0,97 & 0,10 & 1,19 & 50,00 & 3,38 & 5,54 \\
\hline Pterodon emarginatus & 7 & 7,0 & 0,97 & 0,20 & 2,38 & 30,00 & 2,03 & 5,38 \\
\hline Brosimum gaudichaudii & 6 & 6,0 & 0,83 & 0,12 & 1,39 & 40,00 & 2,70 & 4,92 \\
\hline Terminalia actinophylla & 7 & 7,0 & 0,97 & 0,16 & 1,85 & 30,00 & 2,03 & 4,85 \\
\hline Ximenia americana & 5 & 5,0 & 0,69 & 0,04 & 0,48 & 30,00 & 2,03 & 3,20 \\
\hline Mimosa verrucosa & 4 & 4,0 & 0,55 & 0,02 & 0,22 & 30,00 & 2,03 & 2,80 \\
\hline Manihot carthagenensis & 3 & 3,0 & 0,41 & 0,01 & 0,14 & 30,00 & 2,03 & 2,58 \\
\hline Mimosa tenuiflora & 3 & 3,0 & 0,41 & 0,01 & 0,11 & 30,00 & 2,03 & 2,55 \\
\hline Ceiba glaziovii & 2 & 2,0 & 0,28 & 0,04 & 0,44 & 20,00 & 1,35 & 2,07 \\
\hline Bauhinia forficata & 2 & 2,0 & 0,28 & 0,01 & 0,08 & 20,00 & 1,35 & 1,71 \\
\hline Piptadenia stipulacea & 2 & 2,0 & 0,28 & 0,00 & 0,06 & 10,00 & 0,68 & 1,01 \\
\hline Aspidosperma pyrifolium & 1 & 1,0 & 0,14 & 0,00 & 0,05 & 10,00 & 0,68 & 0,87 \\
\hline Bauhinia pulchella & 1 & 1,0 & 0,14 & 0,00 & 0,03 & 10,00 & 0,65 & 0,85 \\
\hline Total & 723 & 723 & 100 & $\mathbf{8 , 8 8}$ & 100 & 1480 & 100 & 300 \\
\hline
\end{tabular}

As espécies, Cenostigma macrophyllum, Combretum duarteanum, Erythroxylum laetevirens, Licania rígida, Campomanesia pubescens, Pityrocarpa moniformis, foram as que apresentaram os maiores IVIs, representando $57,1 \%$ do IVI total (Figura 3). O Índice de Valor de Importância constitui um parâmetro de integração dos aspectos parciais, de forma a combiná-los em uma única e simples expressão, somando-se, para cada espécie, os valores relativos da densidade, frequência e dominância, expondo a importância ecológica relativa de cada espécie. 
Figura 3. Espécies com os maiores valores de importância (IVI), amostrados em uma área de Caatinga na F.F.V., Bom Jesus Piauí, Brasil

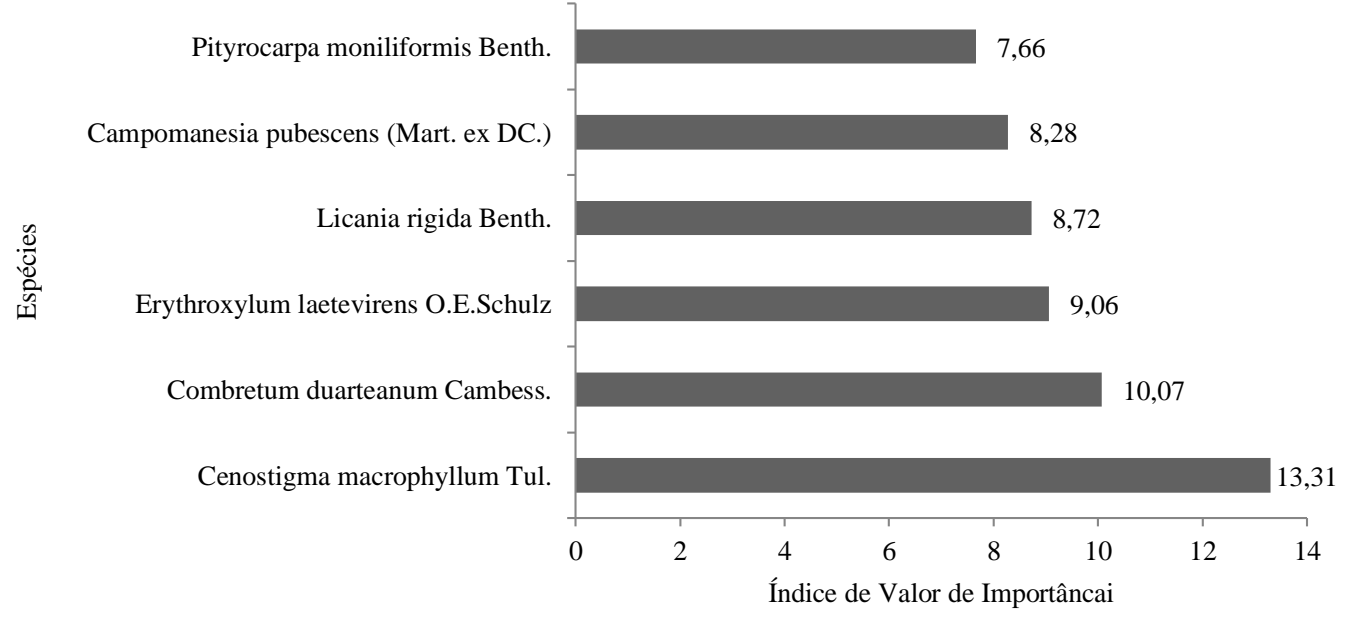

Em se tratando de distribuição por classe de altura, pode-se se constatar que as classes com os maiores números de indivíduos foram a segunda classe até a quinta classe, totalizando $77 \%$ do número de indivíduos amostrados. A quarta classe foi a que deteve o maior número de indivíduos (205), significando dizer que a floresta apresenta na sua maioria, indivíduos de médio porte com altura de 5 a $8 \mathrm{~m}$ (Figura 4).

Figura 4. Número de indivíduos em classes de altura amostradas em uma área de Caatinga na F.F.V., Bom Jesus Piauí, Brasil.

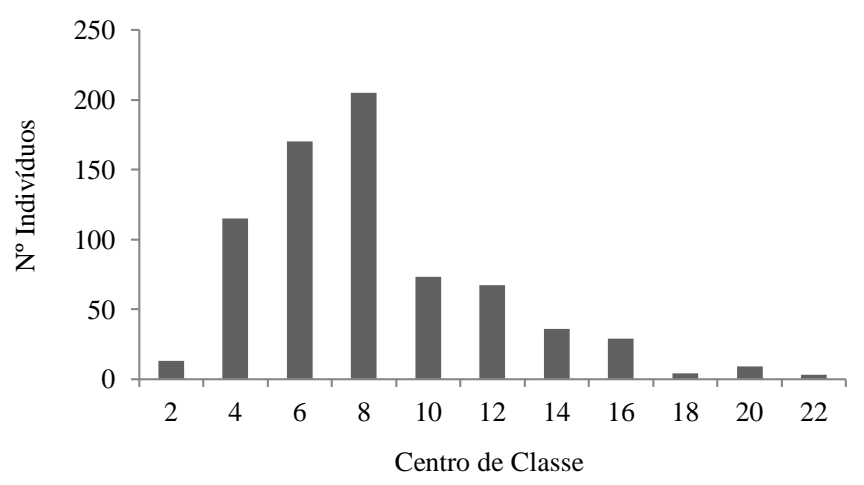

A altura média das árvores inventariadas foi de $6,7 \mathrm{~m} \mathrm{e}$ este valor foi superior ao encontrado por Alves et al. (2013), que analisou a estrutura vegetacional em uma área de Caatinga no município de Bom Jesus, Piauí e obteve o valor de 3,44 m. Também superou os valores obtidos por Lima e Coelho (2015), que estudando a estrutura do componente arbusto-arbóreo de um remanescente de Caatinga no estado do Ceará obtiveram uma altura média de $5,2 \mathrm{~m}$ e por Marangon et al. (2013), que analisaram a estrutura e padrão espacial da vegetação em uma área de Caatinga no Pernambuco e encontraram um valor de $3,63 \mathrm{~m}$. Alves et al. (2013) ressalta que o grau de perturbação encontrado em algumas área de estudos pode ser um fator que influencia diretamente a baixa altura média das árvores encontradas nessas comunidades. Portanto, o valor superior aqui encontrado nos permite inferir que as condições naturais em que se encontra o fragmento estudado são mais preservadas do que as áreas dos levantamentos aqui comparados.
Os valores referentes à distribuição diamétrica podem ser observados na (Figura 5). Observa-se que 430 indivíduos concentram-se na primeira classe diamétrica correspondendo a $60 \%$ do total de indivíduos amostrados; na segunda classe cerca de 212 indivíduos estão presentes o que corresponde a $30 \%$ do número total e a terceira classe apresentou 68 e $9,40 \%$ do número total; sendo 14 indivíduos restantes pertencentes às classes maiores. A predominância de indivíduos nas primeiras classes de diâmetro, apresentando padrão de $\mathbf{J}$ invertido, enfatiza o padrão normal para floresta inequiâneas (ALVES et al., 2013; LIMA; COELHO, 2015; GUEDES et al., 2012).

Em se tratando do valor do diâmetro Médio, este trabalho apresentou um valor de $11,22 \mathrm{~cm}$, o qual se mostra superior aos dois valores encontrados por, Ferraz (2014), que estudando a estrutura do componente arbóreo-arbustivo da vegetação em duas áreas de Caatinga no município de Floresta/PE, encontraram valores de 3,06 e $3,74 \mathrm{~cm}$. O diâmetro Máximo foi inferior à área estudada por Lemos e Rodal (2002), que encontraram um valor de $75,12 \mathrm{~cm}$, enquanto esse estudo apresentou $31,83 \mathrm{~cm}$.

Figura 5. Distribuição diamétrica dos indivíduos amostrados em uma área de Caatinga na F.F.V., Bom Jesus Piauí, Brasil

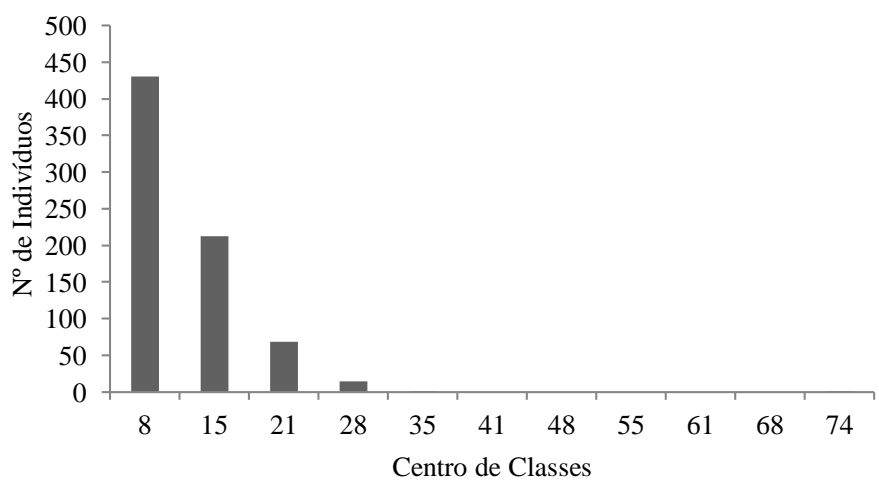

Analisando a diversidade do remanescente de Caatinga estudado, o valor do Índice de Diversidade de Shannon $\left(\mathrm{H}^{\prime}\right)$ encontrado para esta área corresponde a 2,70 nats.ind ${ }^{-1}$, este valor é superior aos valores de 0,23 e 1,50 encontrados por Holanda et al. (2015), que estudaram a estrutura da vegetação em remanescentes de caatinga com diferentes históricos de perturbação em Cajazeirinhas (PB), e por Ferraz et al., (2014), que analisaram a estrutura do componente arbustivo- 
arbóreo da vegetação em duas áreas de caatinga, no município de Floresta, Pernambuco, onde obtiveram 2,10 nats.ind ${ }^{-1}$ e por Marangon et al. (2013) que analisaram a estrutura e padrão espacial da vegetação em uma área de Caatinga e constataram, 2.11 nats.ind ${ }^{-1}$. Alves et al. (2013), em uma análise da estrutura vegetacional em uma área de Caatinga no município de Bom Jesus, Piauí, obtiveram o valor de 2,96 nats.ind $^{-1}$; Leite et al. (2015), analisando quantitativamente a vegetação lenhosa da Caatinga em Teixeira, PB, 3,06 nats.ind ${ }^{-}$ 1 , todos estes autores observaram valores superiores ao encontrado neste estudo.

De um modo geral, o valor encontrado neste trabalho é considerado médio e representativo do padrão de diversidade conhecido para a Caatinga, devido grandes extensões desse bioma se encontrarem antropizada. É de suma importância enfatizar que, pelo fato da Caatinga apresentar diversas fitofisionomias, os estudos realizados neste bioma adotam diferentes processos de amostragem, níveis de inclusões, influenciando a ocorrência de variações nos valores de diversidade.

O valor calculado para o Índice de Dominância de Simpson (C) observado neste estudo foi de 0,88 sendo semelhante ao encontrado por Marangon et al. (2013) de 0,84 e menor do que 0,99 que foi observado por Leite et al. (2015). Tal índice ocorre na escala de 0 a 1 , sendo que os valores próximos de 1 indicam maior diversidade. $O$ índice de equabilidade de Pielou (J') obtido foi de 0,80, o que indica que não há uma única ou poucas espécies que predominem sobre as outras, ou seja, quanto menor este valor, menor é a diversidade e maior é a dominância de uma ou poucas espécies. $\mathrm{O}$ valor encontrado neste estudo foi maior do que aqueles encontrados por Calixto Junior e Drumond (2015), que analisando e comparando dois fragmentos de Caatinga em Petrolina, PE, encontraram valores de 0,50 e 0,78 . No entanto apresentou valor inferior aos observados por Guedes et al. (2012) e Leitão et al. (2014), respectivamente de 0,82 e 0,89 .

\section{CONCLUSÃO}

O fragmento é um ecótono vegetacional, com predomínio de espécies típicas da Caatinga. Fabaceae e Combretaceae foram às famílias que apresentaram o maior número de espécies arbustivo-arbóreas na área.

As espécies que se destacaram com melhor caracterização no fragmento estudado foram Cenostigma macrophyllum, Combretum duarteanum, Erythroxylum laetevirens, Licania rígida, Campomanesia pubescens, Pityrocarpa moniformis e Hymenaea stigonocarpa, representando 63,41\% de valor de importância na área.

\section{REFERÊNCIAS}

AGUIAR, R. de B; GOMES, J. R. de C. Projeto cadastro de fontes de abastecimento por água subterrânea, Piauí: Diagnóstico do município de Bom Jesus do Piauí- CPRMFortaleza, 2004.

ALVES, A. R.; RIBEIRO, I. B.; SOUSA, J. R. L.; BARROS, S. S.; SOUSA, P. R. Análise da estrutura vegetacional em umaárea de caatingano municípiode bom jesus, piauí. Revista Caatinga, Mossoró, v. 26, n. 4, p. 99-106, 2013.
ALVES, J. J. A.; ARAÚJO, M. A.; NASCIMENTO, S. S. Degradação da caatinga: uma investigação ecogeográfica. Revista Caatinga v.22, n3, p 126-135,2009.

ANDRADE-LIMA, D. The caatingas dominium. Revista Brasileira de Botânica, v. 4, p. 149-153, 1988.

ANDRADE, L.A.; PEREIRA, I.M.; LEITE, U.T.; BARBOSA, M.R.V. Análise de cobertura de duas fitofisionomias de caatinga, com diferentes históricos de uso, no município de São João do Cariri, Estado da Paraíba. Revista Cerne, Lavras (MG) v. 11, n. 3, p.253-262, 2005.

APG IV-ANGIOSPERM PHYLOGENY GROUP. An update of the Angiosperm Phylogeny Group classification for the orders and families of flowering plants: APG IV. Botanical Journal of the Linnean Society. v. 181, p. 1-20, 2016.

BULHÕES, A.A.; CHAVES, A.D.C.G.; ALMEIDA, R.R.P.; RAMOS, I.A.N.; SILVA, R.A.; ANDRADE, A.B.A.; SILVA, F.T. Levantamento florístico e fitossociológico das espécies arbóreas do bioma caatinga realizado na Fazenda Várzea da fé no município de Pombal-PB. Intesa, Pombal, v. 9, n. 1, p. 51-56, 2015.

CALIXTO JÚNIOR, J. T.; DRUMOND, M. A. Estudo comparativo da estrutura fitossociológica de dois fragmentos de Caatinga em níveis diferentes de conservação. Pesquisa Florestal Brasileira, Colombo, v. 34, n. 80, p. 345-355, 2014.

CASTRO, A. A. J. F.; CASTRO, A. S. F.; FARIAS, R. R. S. de.; SOUSA, S. R. de.; CASTRO, N. M. C. F.; SILVIA, C. G. B. da.; MENDES, M. R. de A.; BARROAS, J. S.; LOPES, R. N. Diversidade de espécies e ecossistemas da vegetação remanescente da Serra Vermelha, área de chapada, municípios de Curimatá, Redenção do Gurguéia e Morro Cabeça no Tempo, Sudoeste do Piauí. Publicação Avulsa Conservação e Ecossistemas. 23; 2009. p. 1-72.

CHAVES, A. D. C. G.; SANTOS, R. M. S.; SANTOS, J. O.; FERNANDES, A. A.; MARACAJÁ, P. B. A importância dos levantamentos florístico e fitossociológico para a conservação e preservação das florestas ACSA Agropecuária Científica no Semiárido, v. 9, n. 2, p. 43-48, 2013.

DIAS, P. M. S.; DIODATO, M. A.; GRIGIO, A. M. Levantamento fitossociológico de remanescentes florestais no município de Mossoró-RN, Caatinga, Mossoró, v. 27, n. 4, p. 183-190, 2014.

FELFILI, J. M.; REZENDE, R. P. Conceitos e métodos em fitossociologia. Universidade de Brasilia, Brasilia, 2003. p.44-53.

FERRAZ, R. C.; MELLO, A. A.; FERREIRA, R. A.; PRATA, A. P. N. Levantamento fitossociológico em área de caatinga no monumento natural grota do angico, Sergipe, Brasil. Caatinga, Mossoró, v. 26, n. 3, p. 89-98, 2013. 
FERRAZ, J. S. F.; FERREIRA, R. L. C.; SILVA, J. A. A.; MEUNIER, I. M. J.; SANTOS, M. V. F. Estrutura do componente arbustivo-arbóreo da vegetação em duas áreas de caatinga, no município de floresta, Pernambuco. Revista Árvore, Viçosa, v.38, n.6, p.1055-1064, 2014.

GARIGLIO, A. M. A rede de manejo florestal da Caatinga. . In: GARIGLIO, M. A.; SAMPAIO, E. V. S.B.; CESTARO, L. A.; KAGEYAMA, P. Y. (orgs). Uso sustentável e conservação dos recursos florestais da Caatinga. Brasília, Serviço Florestal Brasileiro, 2010. Cap.4, p. 199-204.

GUEDES, R. S.; ZANELLA, F. C. V.; JÚNIOR, J. E. V. C.; SANTANA, G. M.; SILVA, J. A. Caracterização florísticofitossociológica do componente lenhoso de um trecho de caatinga no semiárido paraibano. Revista Caatinga, Mossoró, v. 25 , n. 2 , p. $99-108,2012$.

HOLANDA, A. C.; LIMA, F. T. D.; SILVA, B. M. DOURADO, R. G.; ALVES, A. R. Estrutura da vegetação em remanescentes de caatinga com diferentes históricos de perturbação em Cajazeirinhas (PB). Revista Caatinga, Mossoró, v. 28, n. 4, p. 142 - 150, 2015.

LEITE, J.A.N.; ARAÚJO, L.V.C.; ARRIEL, E.F.; CHAVES, L.F.C.; NÓBREGA, A.M.F. Análise quantitativa da vegetação lenhosa da Caatinga em Teixeira, PB. Pesq. flor. bras., Colombo, v. 35, n. 82, p. 89-100, 2015.

LEMOS, J. R,; RODAL, M. J. N. Fitossociologia do componente lenhoso de um trecho da vegetação de Caatinga no Parque Nacional da Serra da Capivara Piauí, Brasil. Acta. Bot. Bras. v. 16, n.1. p. 23-42, 2002.

LEITÃO, A. C.; VASCONCELOS, W. A.; CAVALCANTE, A. M. B.; TINÔCO, L. B. M.; FRAGA, V. S. Florística e estrutura de um ambiente transicional caatinga-mata atlântica. Revista Caatinga, Mossoró, v. 27, n. 3, p. 200 - 210, 2014.

LIMA, B. G.; COELHO, M. F. B. Estrutura do componentearbustivo-arbóreo de um remanescente de caatinga no estado do Ceará, Brasil. Cerne, v. 21, n. 4, p. 665$672,2015$.

MARANGON, G. P.; FERREIRA, R. L. C.; SILVA, J. A. A.; LIRA, D. F. S.; SILVA, E. A.; LOUREIRO, G. H. Estrutura e padrão espacial da vegetação em uma área de caatinga. Floresta, Curitiba, v. 43, n. 1, p. 83-92, 2013.

MILLER-DOMBOIS, D: ELLEMBERG, H. Aims end methds of vegetation ecologe: New York: Jhon wily e Sons, 1974.p.447.

MONTEIRO, E. R.; MANGOLIN, C. A.; NEVES, A. F. das; ORASMO, G. R.; SILVA, J. G. M. da; MACHADO, M. F. P. S. Genetic diversity and structure of populations in Pilosocereus gounellei (F.A.C.Weber ex K.Schum.) (Cactaceae) in the Caatinga biome as revealed by heterologous microsatellite primers. Biochemical Systematics and Ecology, Oxford, v. 58, n. 2, p. 7-12, 2015.
SANQUETTA, M. N. I.; CORTE, A. P.; SANQUETTA, C. R.; RODRIGUES, A. L.; MONGON, Diversidade e estrutura fitossociológica da caatinga na região de brumado - BA. Enciclopédia Biosfera, Goiânia, v. 10, n. 17, p. 2157- 2167, 2014.

SHEPHERD, G. J. Fitopac - Manual do usuário. Departamento de Botânica, Universidade Estadual de Campinas, Campinas. 2011.

SAMPAIO, Y; BATISTA, J. E. M. Desenvolvimento regional e pressões antrópicas no bioma caatinga e sua biodiversidade: áreas e ações prioritárias para a conservação. Ministério de Meio Ambiente, Brasília, 2004. Cap. 3, p. 124-311. 